$\mathrm{Al}, \mathrm{Si}, \mathrm{P}$ and $\mathrm{S}$, for $\mathrm{Cl}$, regularly diminish if we take the amount for one atom of $\mathrm{Cl}$ in each case; but if we take the actual maximum amount of $\mathrm{Cl}$ with which each element in the series combines, a very different result comes out, because while $\mathrm{Na}$ combines with one atom of $\mathrm{Cl}, \mathrm{Mg}$ combines with two, and $\mathrm{Al}$ with three, and so on. This leads us to make a distinction between the intensity and quantity of chemical affinity, so that while the intensity of affinity in this case regularly diminishes, the quantily rises to a maximum in $\mathrm{Al}$, and then diminishes towards S. There is thus a spreading out of affinity which lowers its intensity, and in this there seems to me a gradual approach to solution. I have traced the same phenomena in some oxides, and it is interesting to note that the atomic weight of $\mathrm{Al}$, whose affinities for $\mathrm{Cl}$ and $\mathrm{O}$ are nearly equal, is almost exactly midway between the atomic weights of $\mathrm{O}$ and $\mathrm{Cl}$. It is, so to speak, the point where the two curves of affinity cross one another. On the one side the affinity for $\mathrm{Cl}$ relatively to that for $\mathrm{O}$ increases, and on the other side decreases. This may throw some light on the peculiar properties of Al. Fe, which is in many respects analogous to $\mathrm{Al}$, and has an atomic weight about twice that of $\mathrm{Al}$, and almost midway between $\mathrm{Cl}$ and $\mathrm{Br}$, shows somewhat similar relations towards $\mathrm{Cl}$ and $\mathrm{O}$. It is also to be noted that while the maximum affinity for $\mathrm{Cl}$ is at $\mathrm{Al}$, that of $\mathrm{O}$ is at $\mathrm{Si}$. It would be interesting to trace curves of intensity and quantity for other elements such as $\mathrm{H}$ and S. Much light might be thrown on many chemical facts.

(2) If we take the heats of combination of $\mathrm{Cl}, \mathrm{Br}$, or $\mathrm{I}$, with any eleinent, the law seems to be that the amount of heat diminishes as the atomic weights of $\mathrm{Cl}, \mathrm{Br}$, and I increase, modified, however, by the atomic weight of the element with which they combine. Thus, take what may be called the normal case, viz. combination with hydrogen, we have

$$
\begin{aligned}
& \text { Atomic weight of } \mathrm{Br}=80 \quad \text { of } \mathrm{I}=\mathrm{I} 27
\end{aligned}
$$

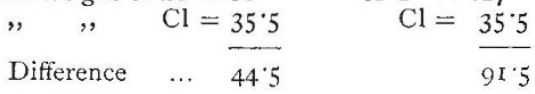

Ifeat of combination $\mathrm{HCl}=22,000 \quad$ of $\mathrm{HCl}=+22,000$

$$
\text { " } \quad \text { Difference } \quad \ldots \quad \frac{\mathrm{I} B \mathrm{r}, 560}{28,040}
$$

Now, 44'5:91'5:: I3,560:28,040 almost exactly. With Al again the above differences are as under-

$$
\begin{aligned}
& \text { Heat of combination } \mathrm{AlCl}_{3}=160,980 \\
& \text { " , } \quad \mathrm{AlBr}_{3}=119,720 \\
& \text { Difference .. } \quad \overline{41,260} \\
& \text { of } \begin{aligned}
\mathrm{AlCl}_{3} & =160,980 \\
\mathrm{AlI}_{3} & =70,590
\end{aligned}
\end{aligned}
$$

Now it is evident these are not exactly in same proportion as the $\mathrm{H}$ compounds, and with $\mathrm{Na}$ and $\mathrm{K}$ compounds the dis crepancy is even greater, but still near enough to suggest the general law as stated above.

(3) If the explanation given of crystallisation be correct, we may go a step further. If we take water alone without any salt in solution, there will be, in my view, attraction between the $\mathrm{H}_{2}$ of one molecule and the $\mathrm{O}$ of another, and vice versî, and if the heat of the liquid be diminished sufficiently, that attraction will cause cohesion of the molecules, and will produce solid water or ice, the regular structure of which is caused by the symmetrical arrangement of the atoms. This again leads on to solids in general, for there is little doubt that atoms of the same kind have affinity one for the other; and thu; the various conditions of matter, solid, liquid, and gaseous, may be due to chemical affinity of the constituent atoms, modified in various ways by the kinetic energy of the system.

It will thus be seen that my view of chesnical affinity is quite opposed to the idea of its being a sort of arbitrary force acting in units or bonds, but I consider it acts between all atoms of matter, whether of the same or different kinds in varying degrees of intensity and quantity, producing combination of more or less stability, graduating fro $n$ the so-called mechanical mixture of clay and water up to the irresolvable molecules of the permanent gas, condensing by its action the gas into the li juid, and the liquid into the solid, chemical compounds being combinations in definite proportions of more or less stability. In fact, in this case as in all others, there are no hard and fast lines in Nature, but every phenomenon graduates by almost imperceptible degrees into another.

\section{THE JAPANESE NATIONAL SURVEY AND ITS RESULTS}

DURING the past five years a work of great national and scientific importance has been proceeding in Japan; little has been heard of it in Europe, and none of its results have been visible amongst us in England until within the last few months. The Japanese National Survey, under the superintendence of Dr. Naumann, furmerly Professor of Geology in the University of Tokio, has lluring the period above mentioned been steadily progressing; it has revealed hitherto unknown features of the country, and has thrown a flood of light on its geography, geology, and resources, actual and possible. A period has now been arrived at in the history of the Survey : its Director, after five years' labour at this particular work, and as many more in the Chair of Geology in the University of Tokio, returns to Europe, leaving the task to be carried out by the Japanese whom he has trained. Some tangible results of the work have, as already mentioned, been for the first time placed before the European public. In the rooms of the Royal Geographical Society might a short time ago be seen by any one who desired to do so a series of maps, printed and manuscript, with numerous plans, illustrations, and sketches, exhibited by Dr. Naumann, and representing to some extent the work of five years. Samples of these were also to be seen at the Exhibition of Geographical Appliances in Great Marlborough Street, amongst others an orographic map of Jap in, and several illustrations-one of the mountain summits in the neighbourhood of the active volca'so Asamayama being especially striking. The present, then, seems a suitable time for describing the Survey, the work it has set before it, that which it has succeeded in doing so far, and the effect of its work on our knowledge of the country.

When Dr. Naumann laid before the Japanese Government, about six years ago, the plan for a national survey, it was based mainly on economical considerations. It was pointed out that by means of such a survey the resources of the country, hitherto undeveloped, and to a considerable extent unknown, would be investigated systematically. At tl:e commencement of the undertaking there were hardly any maps in existence that could be utilised with safety. The work was facilitated by the materials derived from a Japanese astronomical-geodetic survey carried out at the beginning of the present century, which fixed the position of the coast-line and the courses of some of the main roads. The coast surveys of the English Admiralty, also, and of the navies of other countries, as well as the few results of the trigonometrical survey of Japan, were found of use. But the interior of the country, in all that related to orography and geology, was still a terra incognita. In every other respect those rough Japanese compilations of older map-work of a medireval type, though worked out by the application of some of the principles of European cartography, were totally insufficient. Hence at the outset it was necessary to undertake a topographical survey, so that not only matter, but also space, became the object of investigation. From the beginning the necessity of combining observations with measurements was emphasised. Inasmuch as the economical position of the country depends on agriculture, special attention had to be paid to the relations between the qualities of the soil and its cultivation. Hence the Survey started with three departments in. trusted with field-work-one topographical, the second geologi$\mathrm{cal}$, and the third agronomical. A fourth, the chemical section, was created to investigate and test the materials collected by the geological and agronomical sections as to their composition and technical applicability. The plans laid before the Government, and approved, placed the scale of the maps, which were to be published in three series corresponding to the three divisions of the Survey-one topographical, one geological, and one agronomi$\mathrm{cal}$, at $\mathrm{r}: 200,0=0$. The maps were to be $0.456 \times 0.277$ metres for publication, and each series was to contain ninety maps, each of which corresponded to half a degree division, reckoned on the meridian of Greenwich. Two editions, one in English and one in Japanese, were to have been published. The scale for the field-work was I : 50,000. Subsequent experience demonstrated the substantial accuracy of these plans. It is of course essential in surveys like this that the various divisions should work side by side, and advance with equal and regular steps. But a consequence of the conditions under which work of this kind is conducted in Japan was that this co-operation, which was so necessary to 
the common aim, could not be carried out. The agronomical and chemical sections ultimately came under the sole direction of a Japanese Commissioner, and only the topographical and geological sections remained together under the immediate control of the Director who had laid the foundation of the whole undertaking. In order to understand the ill-effect of this division, it is only necessary to mention that the agronomical section worked on a different scale from the topographical and geological, and did topographical work for its own purposes, independent of that done by the topographical section !

The difficulties at the outset were numerous and important. First of all there were those connected with the nature of the work itself. The Japanese chain of islands is little more than a huge and complicated range of mountains, which is in parts hardly passable. Travelling along the main roads in Japan is not always very pleasant, but there are no particular hardships. Amongst the mountain", however, progress can only be made ursder great difficulties; and when a survey has to be made in these regions it demands all the energy and strength of a very strong man. It was necessary, too, in the present instance, in view of the economical wants of the country, to do the work in the shortest possible time. The period originally arranged was twelve years for the whole work; and what has been actually done since the beginning showed that it was possible to complete the Survey in this time had the staff been complete and the proposed organisation strictly disciplined for, and directed to, the purpose in hand, as might have been done. But, in fact, the staff never was complete, and the regular and constant prosecution of the Survey in course of time became more and more difficult, mainly owing to financial considerations. The year before last, for example, no field-work was done at all for this reason. At the outset, too, the training and educating of the assistants and cartographers presented great difficulties, which, owing to the energy and intelligence of the Japanese cooperators, were ultimately overcome. Again, when the stage of publishing was reached, obstacles of a peculiar kind were met with. To publish the maps abroad was not to be thought of The Department had to pay the cost of publishing out of its own funds, and the work had to be carried out by Japanese. Experiments were made with lithography and heliogravure, but it is found impossible to adopt either of these methods in Japan. Ultimately the Toyodo Engraving Company in Tokio was intrusted with the work, under the constant superintendence and control of the clirector, and it is curious to note that the maps are all etched on copper, not engraved. Much more might be said of the difficulties which had to be overcome in this wholly new undertaking in Japan; but a commencement was made with the work towards the end of 1880 . It soon appeared that the plans of the Survey could only be successfully carried out by a reconnaissance of the whole country in the first place. It appeared necessary to obtain first a general view of the conditions of Japan before the special and main work could be effectually coinmenced. The broad features, internal and external, of the mountain system of the country had to be ascertained, particularly for the purpose of allowing uniform representation in the special maps to be published later on. The Iirector commenced this preliminary survey early in $188 \mathrm{I}$, and decided to prosecute it as far as possible in person. This reconnaissance was completed in the beginning of $\mathbf{1} 884$, with a little help from assistants in regard to subordinate details. As an example of the work which this entailed, it may be mentioned that in two years he travelled, mostly on foot, 2000 miles, and that during the five years he was engaged in the work his routes covered about 5000 miles. The surveys in $188 \mathrm{I}$ lasted from May to November, in 1882 from September to December, and the last great journey was from July 1883 to February I884. The intervals which were spent in the capital were fully occupied; the orographical and geological sketch-maps (recently exhibited in London), as well as many others, were then produced. On this general survey of the country a topographical and geological map on a scale of $I: 400,000$, in five large sheets, was prepared. The first of these, embracing the topography of Northern Japan, has already been published, and might have been examined with others in the Royal Geographical Society. The other parts are in hand, and the record is doubtless already complete in manuscript.

Both in the reconnaissance and the principal survey, the method employed in the field-work was partly that of flying surveys. The main object was to obtain in the shortest possible time a view of the natural conditions of the country, and to produce a map which would be useful for economical and scientific purposes. The very detailed surveys of European countries could not, therefore, be taken as examples to be followed. The fundamental consideration was, above all, the economical requirements of the country. Even for military purposes in Japan, a smaller scale, allowing of the application of simpler methods and more rapid progress, is preferable for field and map work. 'In Tokio there is also a Survey Department attached to the General Staff, but it is based on Western methods, and on account of the very large scale adopted many generations must elapse before it is completed. In 1884 , when disturbances broke out in the Saitama prefecture, the military authorities discovered their lack of maps, and they were compelled to obtain maps of the district from the Geological Survey. After this experience, and after the publication of the first sheets of the special map of the Survey, the General Staff would no doubt readily understand the advisability of a system such as that applied by the Geological Survey. During recent years in Japan interesting results were collected respecting the methods necessary for surveys where rapid progress is required. With regard, for instance, to the amount of work which can be performed in a limited time, the sketches exhibited in the Royal Geographical Society prove of much interest for military, exploring, and colonial surveys. It happens frequently that the practical geographer is compelied to explore or survey a given region in the shortest possible time. During the topographical and geological field-work of the Japan Survey, one of the most important rules observed was that of plotting the relations of space measured or observed in the particular places at once, and according to a definite scale ( $\mathrm{I}: 50,000)$. The first designs of the maps were, so to say, made in the field in the face of the objects to be represented. In this way the work of the topographer was made as independent as possible of that of the cartographer; under any other plan the final result would be moxe arbitrary. The amount of field-work done each day appears to reach the highest limit attainable. In $\mathbf{x} 88 \mathrm{r}$, for instance, Dr. Naumann surveyed, in some cases, routes of 32 kilometres in length, and this during the hottest summer months, and in difficult mountainous country. The daily average of Dr. Naumann during the reconnaissance surveys of I88I amounted to 20 kilometres, while the average for the Japanese assistants was 12 kilometres. With regard to the degree of accuracy of the surveys thus made, it appears from an article on them, published in Petermann's Mittheilungen for January I884, that the results, even with this great rapidity, were highly satisfactory. The route Miyako-Morioka, in Northern Japan, for example, shows an error of only 0.6 per cent. for the distance between the terminal points, which in a straight line is 68 kilometres, while the actual route surveyed is 100. For reconnaissance purposes this route was surveyed in five days.

At the commencement of the Survey the technical staff consisted of four Europeans-viz. a director, topographer, agriculturist, and chemist-and twenty-two Japanese assistants-viz. one geologist, five topographers, five agriculturists, five chemists, and six draughtsmen. The foreign chief of the agricultural section left the Japancse service at the beginning of $188 \mathbf{I}$, and the foreign topographer a year later. The services of another foreign agriculturist were obtained at the end of 1883 . At present the technical staff consists of two Japanese directors, one European in charge of the agricultural section, and thirty Japanese assistants. The results of the Survey are, in the first place, in the shape of maps, of which the following is a list :-

A. General Maps on the scale of $\mathbf{1}: 874,000$ (at present in manuscripts.

(I) Geological map by Dr. Nammann and his geological assistants. On this map the distribution of the following geological groups and rocks shown:-Primitive gneiss (violet); crystalline schists (light rose carmine) ; Palæozoic group (neutral tint) ; Mesozoic group, Triassic, Jurassic, and Cretaceous (blue); Tertiary (light green); volcanic tuff, corresponding to very modern Tertiary (light yellow); granite, quartz porphyry, porphyry, porphyrite, diorite, diabase, and volcanic rocks.

(2) Oroplastic map by Dr. Naumann and his topographical assistants. The surface shape is represented by horizontal layers of 200 metres; the depths of the surrounding seas are shown on the same system. The mountains are marked by successive shades of brown, the sea by shades of blue. This map was in the late Exhibition of Geographical Appliances. 
These two maps are mainly compiled from Dr. Naumann's reconnaissance surveys.

(3) Magnetic map by S. Sekino, representing the isogonic, isoclinic, and isodynamic lines of Japan, constructed from about 200 magnetic observations made at as many different stations.

(4) Map of the great historical earthquakes, volcanoes, solfataras, and hot springs of Japan, by Dr. Naumann and two of his assistants. The relative frequency of earthquakes in different parts of the country is indicated by different shades of brown. The limits of the areas of disturbance of some of the most remarkable earthquakes are likewise given.

B. Maps Printed and Published.

(5) Reconnaissance map, Division I., containing the northern part of the main island, from the original survey of Dr. Naumann and his assistants (Tokio, I884). As already mentioned, this map is on the scale of $I: 400,000$. The mountains are represented by curves of equal height, 40 metres apart. The map is printed in three colours-the mountains brown, the water blue, while the skeleton and writing are black. The surface shape is clearly shown, and the system of representing the mountains is peculiar, and novel at least in a map of such small scale. The curves of equal height are directly used for the production of shades, which latter indicate the amount of slope. Great difficulty was encountered in reproducing this map. There can be no doubt that 40 -metre curves applied to a 400,000 scale map represent the utmost limit attainable at present. In the case of an inclination of $45^{\circ}$, which occurs here and there, though rarely, the curves approach each other so closely that a zone of $\mathrm{I} \mathrm{mm}$. in breadth contains no less than ten lines! There are two different editions of the reconnaissance map-one with Roman, the other with Japanese, lettering. On other grounds all these maps are of interest, for they are the first artistic reproduction of the results of a regular topographical Survey in the far east of Asia.

(6) The three first sheets of the special Survey, showing the topography of the section Yokohama, Idsu, and Kadzusa. Here also there are two editions. Scale $1: 200,000$, and the mountains are shown by curves of equal height 40 metres apart.

(7) Index-sheet, containing the divisions of the whole country into five sections for purposes of the publication of the recon naissance map, and into ninety sections for the special map. A short statement gives the progress of the Survey up to 1884 while the various signs employed in the maps are explained.

Besides the maps here specified, numerous designs, geological sections, landscape representations, tables, \&c., have been made. A large number of practical reports were made for the Government, some of which have been published, but only in Japanese, and they are therefore inaccessible to the rest of the world. Among the papers thus furnished by the Director him self were reports on the waste of ores in Japan, on slate deposits and their utilisation, on Japanese building-stones, on the moving sand-dunes on the coast of Satsuma and how to fix them, on Japanese mineral springs, on the occurrence of gold and copper in various localities, and others.

As to the scientific results obtained by the Survey, they are of much general interest, but it is impossible in the space at our disposal to do more than refer to them cursorily. Those specially interested in the geological work may consult Dr. Naumann's book on the subject, "Bau und Entstehung der japanischen Inseln" (Berlin, Friedländer Sohn, I885). Almost all systems have a part in building up the colossal mountainrange forming the Japanese islands. The occurrence of Devonian, Carboniferous, Triassic, Jurassic, Cretaceous, and Tertiary, was established by well-characterised fossils. A remarkable discovery of Upper Cretaceous Ammonites was made in the Island of Yezo, which Dr. Naumann proves are identical with Indian species of corresponding age. The considerable collection of Tertiary plants is now being studied by Prof. Nathorst, and his researches promise some interesting results, as appears from some preliminary notes already published by him. A monograph on Jurassic plants by Mr. Yokoyama, one of Dr. Naumann's assistants, will shortly appear. In early Tertiary times the Japanese islands contained numbers of elephants, identical with the celebrated species belonging to the old Indian Siwalik fauna (Dr. Naumann, "On Japanese Fossil Elephants," "Paläontographica," xxviii. 1). Triassic strata have yielded important fossils corresponding to the well-known Monotis salinaria of the Alps. Another important result of the Survey is the discovery of Radiolarian slates in almost every part of the archipeiago. These are of great age, being probably older than the Carboniferous limestone, and they are nothing else than hardened mud of the deepest parts of the ocean bottom. Radiolarian mud occurs at present in depths of from 4200 to 8400 metres in the western and central parts of the Pacific Ocean, as ascertained by the Challenger Expedition. The mud, as well as the slates, is in great part made up of the microscopical skeletons of Radiolarians, and we learn that at remote periods the conditions at the greatest depths of the ocean have been nearly the same as at present, and that in Palæozoic times a great part at least of the Japanese chain was deeply submerged beneath the sea. Great scientific value must also be attributed to the results respecting tectonic geology, which are perhaps the most prominent of all. The Japanese island chain is one of the finest examples of a mountain-range of unilateral structure and there cannot be the slightest doubt that it has been shifted by forces acting from the side of the Japan Sea towards the side of the free ocean. Almost all the eruptive and volcanic rocks are confined to a zone facing the Sea of Japan, while the outer zone is for the greater part made up of folded larger masses of Palæozoic and pre-Palæozoic times. Very striking, too, is the great transverse depression, introduced by Dr. Naumann into scientific nomenclature by the name of Fossa Magna, which crosses the main island not far from the capital. It appears that this depression is a kind of fissure or cleft produced by another chain of mountains running from Vries Island to the Bonin Islands. The movements going on in this latter chain may have entered the Japanese chain so as to split it. Some of the largest volcanoes of the country-as for instance the celebrated Fujinoyama-issued from that fissure. An inspection of the geological map shows clearly how the advancing folds were stopped by the Fossa Magna, so that they curve back and go around it. Last, but not least, the results concerning the magnetism of the earth may be mentioned. As shown in the magnetic map mentioned above, the magnetic curves are curiously irregular, and these irregularities have an evident connection with those of the geological structure. The Fossa Magna causes the isogonic lines to describe a large irregular curve, like the folds of the geological strata. Dr. Naumann, we believe, is preparing a paper on this subject for the Royal Society, where a fuller treatment of this phenomenon than he has hitherto given may be anticipated.

It is to be regretted that the Japanese Government does not appear sufficiently aware of the importance of a work such as that carried out by its Geological Survey. Its economical value is probably that which would appeal most strongly to a Government, and of its utility from this point of view there can be no doubt. The fundamental ideas with which the undertaking started should be revived : the various sections of the Survey must advance with even step, otherwise the work cannot fail to be irregular and dislocated. It may be hoped, too, that the Japanese will know how to utilise the invaluable experience laboriously collected by the Survey during the past five years.

\section{UNIVERSITY AND EDUCATIONAL INTELLIGENCE}

CAMBRIDGE.-An Examination for Minor Scholarships at Downing College will be held early in June. These Scholarships will be awarded for Law, or certain branches of Natural Science. Persons who have not entered at any College in the University are eligible to these Scholarships, which will be of the value of $50 l$., and tenable until their holders are of standing to compete for a Foundation Scholarship. Further information will be given by the Tutors of the College.

\section{SCIENTIFIC SERIALS}

Archives Iialiennes de Biologie, tome vii., fasc. I, Rome, February 1886 , contains :- Studies on the drainage of the Roman Campagna, part 5, by C. Tommasi-Crudeli, concludes with the expression of his opinion, based on very numerous facts-(I) that the proposed artificial draining of the Ostian and Maccaresan marshes, and their reclamation, will augment in a great degree the malaria exhalations from these basins and (2) that the hygrometric condition in which the subsoil of the reclaimed district would exist would render it very probable that such malaria exhalations would be persistent. He believes that malaria is produced on the earth, and not on the water, and when an area is covered with a sheet of water, and while it 